\title{
DAMPAK KEGIATAN CORPORATE SOCIAL RESPONSIBILITY (CSR) PERUSAHAAN SEBAGAI MOTOR PENGGERAK PENINGKATAN EKONOMI MASYARAKAT
}

\author{
Handy Nugroho \\ Program Studi Manajemen, Sekolah Tinggi IImu Ekonomi Gentiaras, Bandar Lampung \\ Email : handynugroho2011@gmail.com
}

\section{ABSTRACT}

Every business entity especially a company would want benefit in the form of profit. The profits obtained by the company must be redistributed, not only to the shareholders but also to the company's stakeholders, namely the community. One form of distribution of these benefits is through Corporate Social Responsibility (CSR) activities. At present the activities of Corporate Social Responsibility (CSR) have been carried out by many companies both in the form of physical development and human resource development. Increased physical development and human resource development through CSR are expected to help the government to improve the economic welfare of the people in the area, where the company operates and benefits.

This literature-based research tries to trace the forms of corporate social responsibility that have been carried out by various profit-oriented companies and their impact on the improvement of the economy of the regional communities around the company. Sources of data used as samples in this study are research papers in the form of journals and papers which relate to the role of corporate social responsibility activities carried out by the company towards improving the economy of the people in the area of the company operating. The results of the various studies carried out are then summarized in a general description of whether CSR that has been carried out in Indonesia contributes to improving the economy of the community around the company.

The results of the literature review that have been carried out based on sample research topics found that a large part found there was a significant influence of CSR conducted by the company on improving the economic welfare of the community. The study also concluded that CSR activities in the form of human resource development have a greater impact on improving the economic welfare of the community. We will hope that in the future with the encouragement of the Government, CSR that will carried out by the company can focus to prioritizing activities that develops community economic.

Keyword : corporate social responsibility, human resource development, Profit, stakeholder

\section{PENDAHULUAN}

\subsection{Latar Belakang}

Program Corporate Social

Responsibility (CSR) merupakan bentuk tanggung jawab sosial yang seharusnya wajib dilakukan oleh semua entitas bisnis, terutama perusahaan yang berorientasi profit. Pemerintah mendukung pelaksanaan CSR melalui peraturan perundangan yaitu Undang Undang No.40 tahun 2007 tentang Perseroan Terbatas (UUPT), UU No. 25 Tahun 2007 tentang Penanaman Modal serta peraturan pemerintah No.47 Tahun 2012 Tentang Tanggung Jawab Sosial dan Lingkungan Perseroan Terbatas (PP 47/2012). Pelaksanaan CSR diharapkan dapat lebih berkembang lagi dari sisi kualitas dengan diusulkannya Undang-undang yang mengatur mengenai tanggung jawab sosial. Rancangan Undang Undang (RUU) Tanggung Jawab Sosial akan diperluas pemberlakuan kewajiban pemberian dana tanggung jawab sosial perusahaan (CSR) dengan kisaran 2-3 \% dari Laba Perusahaan. Menurut Hartono Laras, Sekjen Kemensos (Kontan, Rabu 1/8/2018), mengakui, RUU CSR masih mendapat tentangan dunia usaha. "Masih terdapat pemahaman yang belum sinkron, pihak dunia usaha menilai RUU CSR belum perlu," terangnya. Namun, RUU ini diperlukan karena dalam pelaksanaannya masih banyak pengusaha belum menjalankan CSR. 
Di Indonesia kewajiban untuk melakukan CSR lebih diutamakan kepada Perusahaan Tambang dan BUMN. Harapan kedepan dengan terbitnya UU kewajiban ini diperluas untuk setiap entitas bisnis berbentuk PT yang beroperasi di Indonesia. Besaran dana untuk CSR sebaiknya sebesar 1-1,5\% dari laba perusahaan, besaran ini dipertimbangan karena pajak yang ditanggung rata-rata perusahaan di Indonesia berkisar antara 25\% pertahun. Entitas bisnis sebaiknya melihat program CSR bukan hanya sebagai beban saja atau sebatas kedermawanan, namun bagian dari investasi masa depan bagi keberlangsungan (sustainability) entitas bisnis itu sendiri. Untuk mencapai hal tersebut memang diperlukan proses maupun tahapantahapan yang berkelanjutan.

Penghargaan terhadap entitas bisnis dalam melaksanakan CSR yang dilakukan dalam acara Indonesia Corporate Social Responsibility Award II dan CSR Award, Expo and Summit diselenggarakan pada tahun 2018 menunjukkan cukup banyak perusahaan yang telah melakukan CSR dengan baik. Harapan dari diadakannya kegiatan penghargaan tersebut dapat memicu semangat perusahaanperusahaan lain di Indonesia untuk memperbaiki dan mengembangkan program program CSR yang dapat menjawab tantangan sosial dalam rangka membina dan memberdayakan masyarakat agar lebih sejahtera dan mandiri.

Penelitian ini mencoba mengevaluasi apakah kegiatan CSR yang telah dilakukan entitas bisnis (Perusahaan) dapat menjadi motor penggerak dari peningkatan ekonomi masyarakat Indonesia.

\section{TINJAUAN PUSTAKA}

CSR merupakan suatu konsep dimana entitas bisnis mengintegrasikan perhatian social dan lingkungan kedalam interaksi dengan stakeholder yang bersifat wajib (the European commission, 2011). Pada umumnya, CSR dipahami sebagai elemen penting bagi eksistensi reputasi kekinian dan masa depan organisasi, korporasi bisnis, organisasi kemasyarakatan, dan lembaga-lembaga publik dengan mempertimbangkan bahwa sebagian yang diperoleh lembaga-lembaga itu harus kembali pada masyarakat (Fonteneau, 2003). Sebagian memandang, CSR sudah cukup bila dilakukan dalam batas kontribusi bernuansa charity. Namun demikian, sebagian yang lain memandang bahwa korporasi perlu terlibat lebih besar dalam menunjukkan peran kehadirannya di masyarakat dan tidak sekadar dengan menunjukkan kedermawanan (Kotler dan Lee, 2004; Hawkins, 2006; Cooper, 2004; dan Henderson, 2001). Sebetulnya program CSR selaras dengan konsep triple bottom line yang pertama kali digagas oleh J Elkington, 1997 dan ditarik kembali olehnya untuk dilakukan perbaikan (Elkington,2018). Konsep triple bottom line dalam CSR menjelaskan bahwa selain mengejar profit, seharusnya perusahaan juga memperhatikan dan terlibat dalam pemenuhan kesejahteraan masyarakat (people) dan juga berkontribusi aktif dalam menjaga kelestarian lingkungan sekitarnya.

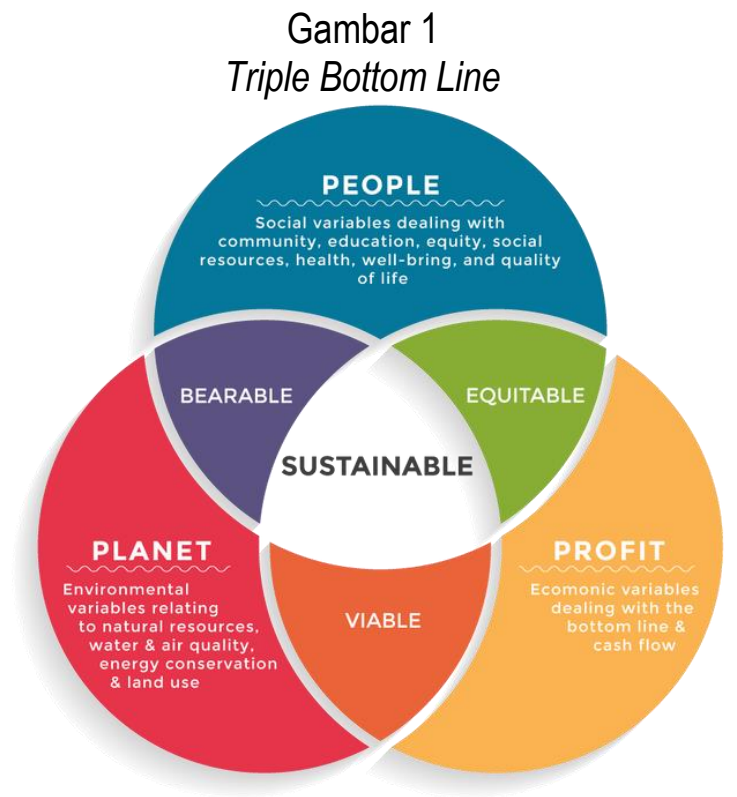

Gambar tersebut menjelaskan bahwa perusahaan harus memperhatikan ketiga aspek pada konsep triple bottom line yang terdiri dari :

a. Profit (Laba) merupakan salah satu unsur yang paling penting dan juga menjadi tujuan utama dari setiap entitas bisnis. Profit merupakan pendapatan yang dapat digunakan untuk menjamin kelangsungan (sustainability) hidup perusahaan. 
b. People (Masyarakat Pemangku Kepentingan); masyarakat adalah salah satu stakeholder yang merupakan bagian terpenting bagi kelangsungan hidup perusahaan, karena masyarakat merupakan salah satu unsur pendukung yang menentukan kelangsungan hidup dan juga perkembangan entitas bisnis. Oleh karena itu perusahaan perlu berkomitmen untuk berupaya memberikan manfaat yang sebaik-baiknya kepada masyarakat sekitar.

c. Planet (Lingkungan); Apabila perusahaan ingin mempertahankan eksistensinya dan agar dapat diterima oleh masyarakat, maka entitas bisnis tersebut juga harus menyertakan pula tanggung jawabnya terhadap lingkungan sekitar entitas bisnis tersebut beroperasi. Perusahaan dengan lingkungan memiliki hubungan sebab akibat, yang apabila lingkungan dirawat dengan baik akan memberikan manfaat yang baik pula bagi entitas bisnis.

Program CSR yang bersifat wajib, diharapkan dapat meningkatkan kesadaran entitas bisnis yang berorientasi profit untuk lebih peduli kepada kehidupan sosial dan lingkungan (ekologis). Guna menelaah pentingnya Corporate Social Responsibility diperlukan secara luas tentang azas manfaat pelaksanaan program CSR bagi masyarakat disekelilingnya. Dalam menentukan program tersebut Kotler (2011: 26) menggarisbawahi lima hal penting yakni perhatian penuh potensi internal dan ekternal, manfaat adanya potensi, tindakan yang baik bagi usahanya, kesadaran akan tindakan yang terus meningkat, dukungan terhadap perubahan perilaku. Guna mengimplementasikan program ini masingmasing institusi diharuskan memiliki langkah strategis antara lain tata kelola yang benar (good governance), memiliki struktur organisasi yang mantap, kepemimpinan yang berwawasan lingkungan, serta memiliki kemampuan kewirausahaan yang tinggi (Hitt dan Hoskisson, 2007: 288).

\section{Sustainability Report}

Menurut Elkington (2007), sustainability report berarti laporan yang memuat tidak saja informasi kinerja keuangan tetapi juga informasi non keuangan yang terdiri dari informasi aktivitas sosial dan lingkungan yang memungkinkan perusahaan bisa bertumbuh secara berkesinambungan (sustainable performance). Sedangkan menurut Global Report Initiative G4 tahun 2013, sustainability report adalah laporan keberlanjutan yang dikeluarkan oleh sebuah perusahaan atau organisasi tentang dampak ekonomi, lingkungan dan sosial yang disebabkan oleh aktivitas sehari-hari.

Sustainability report merupakan istilah umum yang dianggap sinonim dengan istilah lainnya seperti triple bottom line report. Istilah tersebut dipopulerkan pertama kali oleh Elkington (2007) dimana menjelaskan bahwa jika perusahaan menginginkan sustainability terhadap kegiatan usahanya maka haruslah memperhatikan 3P, selain mengejar keuntungan (profit), perusahaan harus terlibat pada pemenuhan kesejahteraan masyarakat (people), dan turut berperan aktif dalam menjaga kelestarian lingkungan (planet). Sustainability report merupakan bentuk laporan keberlanjutan yang dikembangkan oleh Global Reporting Initiative.

Global Reporting Initiative (GRI) adalah lembaga independen yang didirikan pada tahun 1997 di Boston, AS dengan keanggotaan multi profesional seperti organisasi HAM, akuntan, pengusaha, lembaga riset, investor, organisasi lingkungan hidup, dan organisasi buruh berbagai negara. GRI didirikan karena semakin mendesaknya transparansi pengaruh aktivitas bisnis perusahaan baik ekonomi, lingkungan dan sosial sehingga dibutuhkan pedoman untuk menyusun suistainability report bagi perusahaan dalam berbagai ukuran dan sektor usaha di seluruh dunia. Tujuannya antara lain meningkatkan harmonisasi perusahaan terhadap stakeholder baik itu shareholder, manajemen, karyawan atau buruh, investor, pemerintah, organisasi non pemerintah, masyarakat, membantu investor memiliki analisis secara utuh baik teknikal maupun 
fundamental dalam mengambil keputusan investasi, dan lain-lain (Maharani, 2014). Di dalam pengungkapan sustainability report, diperlukan adanya prinsip-prinsip untuk memastikan kualitas informasi dalam laporan. Semua prinsip-prinsip tersebut merupakan hal yang mendasar untuk mencapai transparansi. Kualitas informasi adalah hal yang penting untuk memungkinkan para pemangku kepentingan dapat membuat asesmen kinerja yang logis dan masuk akal, serta mengambil tindakan yang tepat (GRI, 2018). Berdasarkan Global Report Initiative G4 tahun 2018, adapun prinsip-prinsip yang digunakan dalam menentukan kualitas laporan yaitu:

1. Keseimbangan; laporan harus mencerminkan aspek-aspek positif dan negatif dari kinerja organisasi untuk memungkinkan dilakukannya asesmen yang beralasan atas kinerja organisasi secara keseluruhan.

2. Komparabilitas; organisasi harus memilih, mengumpulkan, dan melaporkan informasi secara konsisten. Informasi yang dilaporkan harus disajikan dengan cara yang memungkinkan para pemangku kepentingan menganalisis perubahan kinerja organisasi dari waktu ke waktu, dan yang dapat mendukung analisis relatif terhadap organisasi lain.

3. Akurasi; informasi yang dilaporkan harus cukup akurat dan terperinci bagi para pemangku kepentingan untuk dapat menilai kinerja organisasi

4. Ketepatan Waktu; organisasi harus membuat laporan dengan jadwal yang teratur sehingga informasi tersedia tepat waktu bagi para pemangku kepentingan untuk membuat keputusan yang tepat.

5. Kejelasan; organisasi harus membuat informasi tersedia dengan cara yang dapat dimengerti dan dapat diakses oleh pemangku kepentingan yang menggunakan laporan.

6. Keandalan; organisasi harus mengumpulkan, mencatat, menyusun, menganalisis, dan mengungkapkan informasi serta proses yang digunakan untuk menyiapkan laporan agar dapat diuji, dan hal itu akan menentukan kualitas serta materialitas informasi.

\section{Corporate social responsibility terhadap ekonomi \\ Menurut Prajarto (2015) Dengan} menimbang bahwa setiap korporasi memiliki kedudukan unik di dalam masyarakat, menjadi suatu hal yang wajar bila CSR diterapkan secara berbeda-beda oleh masing-masing korporasi. Program CSR industri perbankan, sebagai contoh, akan berbeda dengan program CSR industri tembakau dan program CSR di Papua juga menjadi wajar bila berbeda dengan program CSR untuk masyarakat pantai utara pulau Jawa.

Terkait hal di atas Marks dan Spencer (2005) dalam hal ini menegaskan bahwa setiap korporasi akan menggunakan pendekatan yang berbeda ketika penyusunan dan pada saat menjalankan program CSR-nya. Persoalan utama yang kemudian terlihat tentunya berpusat pada pijakan yang harus diambil dalam pengembangan ke depan sinergi Pemerintah, perusahaan, dan publik ini. Gayung bersambut saat kesadaran tentang pentingnya ekonomi kreatif muncul di Indonesia (Anonim, 2011).

Tahun 2005, Presiden ke-6 Indonesia menyatakan perlunya meningkatkan kreativitas bangsa dan industri kerajinan. Tahun 2008, disusun cetak biru Pengembangan Ekonomi Kreatif Indonesia. Tahun 2011, diluncurkan platform Komunikasi Ekonomi Kreatif di www.indonesiakreatif.net dan dibentuk Kementerian Pariwisata dan Ekonomi Kreatif. Hal yang kemudian bisa dipahami adalah pengembangan ekonomi kreatif bisa digunakan untuk mempertajam sinergi Pemerintah, perusahaan, dan publik dalam kaitannya dengan penerapan program CSR. Mengacu pada beberapa penerapan yang telah dilakukan sejumlah negara, seperti Thailand yang cukup jeli menggunakan kekuatan ekonomi kreatifnya untuk menghapus citra negatif negara "industri pelacuran" dan Inggris yang mampu mendongkrak kekuatan ekonomi nasional melalui industri musik (Lazzeretti, 2012; serta Kong dan O'Connor, 2010), hal utama yang kemudian layak dipikirkan adalah 
cara mempertajam program dan sinergi antarunsur dalam CSR di Indonesia untuk pengembangan ekonomi kreatif nasional, khususnya bidang media, desain, dan iptek. Studi tentang penerapan program CSR dalam pengembangan ekonomi kreatif berbasis media, desain, dan iptek ini dapat ditilik lebih jauh.

Henry dan de Bruin (2011) dalam
melihat peran industri kreatif pada
pertumbuhan ekonomi kontemporer
menunjukan adanya hubungan pengaruh antara perusahaan-perusahaan yang kreatif dan kewirausahaan terhadap pertumbuhan ekonomi masyarakat. Dengan lebih menekankan pada masalah kewirausahaan ini, mereka berdua meyakini bahwa industri kreatif sangat potensial untuk menumbuhkan semangat kewirausahaan.

Di Indonesia, sebagai contoh, program PMKM Mandiri dari Bank Mandiri telah menciptakan sejumlah enterprenur muda yang kemudian terbukti berhasil menjalankan industri kreatif mereka. Hal ini menjadi salah satu bukti bahwa kekreatifan suatu perusahaan untuk melakukan edukasi pada soft skills kewirausahaan dapat membuka sejumlah peluang usaha dalam industri kreatif. Lebih lanjut mereka berdua menyatakan bahwa meskipun sejumlah negara telah menjalankan kebijakan yang mendukung seni-seni kreatif, masih sedikit kajian yang berfokus pada masalah kewirausahaan untuk industri media, desain, serta ilmu pengetahuan dan teknologi. Pergeseran dari analisis budaya ke pertumbuhan ekonomi serta kemampuan ekonomi kreatif dalam meningkatkan kesejahteraan dan perkembangan ekonomi disampaikan Lazzeretti (2012) dengan mencermati hal-hal yang terjadi di sejumlah kota di Eropa. Dikatakannya, sejumlah kota di Eropa mulai menggunakan seni sebagai amunisi untuk industrinya dengan menggeser diri dari industri tradisional ke industri kreatif. Dengan kata lain, kebudayaan dan kreativitas dapat dipakai sebagai senjata strategis untuk keluar dari suatu krisis ekonomi dan untuk melakukan redefinisi model ekonomi untuk pembangunan berkelanjutan

\section{METODOLOGI PENELITIAN}

Penelitian yang berbasis literatur ini mencoba menelusuri bentuk-bentuk corporate social responsibility yang telah dilakukan berbagai perusahaan yang berorientasi profit dan dampaknya bagi peningkatan ekonomi masyarakat daerah yang berada di sekitar perusahaan tersebut. Sumber data yang digunakan sebagai sampel dalam penelitian ini adalah tulisan-tulisan penelitian berupa jurnal maupun paper yang yang berkaitan dengan peranan kegiatan corporate social responsibility yang dilakukan perusahaan terhadap peningkatan ekonomi masyarakat yang berada di di daerah perusahaan tersebut beroperasi.

Pencarian sampel penelitian ini menggunakan convenience sampling berdasarkan materi yang dapat dicari di google scholar, perpusnas Indonesia dan jurnal-jurnal lain yang terakreditasi. Hasil dari berbagai penelitian yang dilakukan tersebut kemudian dirangkum dalam sebuah gambaran umum apakah CSR yang telah dilakukan di Indonesia memberikan kontribusi terhadap peningkatan ekonomi masyarakat disekitar perusahaan.

Selain itu penelitian ini menggunakan metode kualitatif yang memiliki tujuan descriptive research. Descriptive Research bertujuan untuk mendeskripsikan suatu gejala, peristiwa, kejadian yang terjadi pada saat sekarang. Metode basic research adalah metode yang digunakan saat menjawab suatu main dan mini research yaitu melakukan penelitian langsung ke tempat tempat dimana CSR dilaksanakan. Penelitian juga dilakukan dengan interview/wawancara, observasi, dan analisis dokumen saat melakukan penelitian tersebut.

\section{ANALISIS DAN PEMBAHASAN}

Penelitian kualitas tanggung jawab social (CSR) di 4 negara yaitu Indonesia, Malaysia, singapura dan Thailand yang dilakukan oleh Loh, Low, Sim, Thomas \& Yu (2016) dengan menggunakan indicator CSR menurut Global Initiative Reporting (GRI) menemukan bahwa pelaporan CSR di Indonesia sudah diungkapkan dengan baik dari sisi ekonomi dan sosial indikator namun 
dibutuhkan pengungkapan yang lebih baik lagi untuk indikator tata kelola dan lingkungan. Global Initiative Reporting (GRI) terbagi dalam 4 indikator yang terdiri dari indikator tata kelola perusahaan, indicator ekonomi, indikator lingkungan dan indikator sosial, yang dapat dilihat masing-masih sub-nya di dalam tabel dibawah ini.

Tabel 1.

Indikator Metodologi Pelaporan GRI

\begin{tabular}{ll}
\hline \multicolumn{2}{c}{ Indikator dalam asesmen metodologi Global Reporting Initiative } \\
\hline Governance & Economic \\
\hline Gov 1: Code of Corporate governance & Econ1: Economic Value Generated \\
Gov 2: Governance procedures & Econ 2:Value and supply chain \\
Gov 3: Anti- Corruption and code of ethics Econ 3: Climate change-implications,risk, opportunities & \\
& Econ 4: Investment in non-core business infrastructure \\
& Econ 5: Risk Management \\
\hline Enviromental & Social \\
\hline Env 1: Energy & Soc 1: Diversity and Equal opp \\
Env 2: Water & Soc 2: Labour and Industrial relations \\
Env 3: Waste Management & Soc 3: Occupational health and safety \\
Env 4: Carbon emissions & Soc 4: Training and education \\
Env 5: Biodiversity & Soc 5: Human rights \\
Env 6: Compliance & Soc 6: Community involvement \\
Env 7: Product and service stewardship & Soc 7: Product responsibility \\
& Soc 8 Philanthropy \\
\hline
\end{tabular}

Sumber: Data Indikator GRI, 2108

Tabel 2.

Item Informasi CSR Berdasarkan Sektor Industri

\begin{tabular}{clcc}
\hline No & Sektor Industri & f & $\%$ \\
\hline 1 & sektor finance & 3 & 0.12 \\
2 & Sektor infrastructure & 4 & 0.16 \\
3 & Sektor Pertanian & 8 & 0.32 \\
4 & Sektor Manufactur & 5 & 0.2 \\
& Sektor Consumer & & \\
5 & Goods & 5 & 0.2 \\
\hline & & 25 & 1 \\
\hline
\end{tabular}

Sumber: Data Indikator GRI, 2108

Berdasarkan penelitian di atas, mengungkapkan bahwa indikator CSR yang berkualitas adalah pentingnya pengungkapan atau laporan dari kegiatan CSR yang telah dilakukan entitas bisnis. Pelaporan atau pengungkapan ini umumnya dilaporkan oleh perusahaan-perusahaan Indonesia satu tahun sekali dalam bentuk laporan Sustainability. Dari empat indikator dalam asesmen metodologi GRI , Indikator Governance dan Enviromental adalah indikator terlemah yang dilaporkan oleh perusahaan perusahaan di Indonesia. Oleh karena itu diperlukan peranan lebih dari pemerintah untuk meningkatkan pengungkapan di kedua bidang diatas agar pelaporan CSR yang telah dilakukan perusahaan-perusahaan Indonesia dapat menjadi lebih baik lagi.

Penelitian penelitian yang dilakukan terkait dampak kegiatan CSR terhadap masyarakat diantaranya dilakukan oleh Novita dan Iriani (2016) menemukan program CSR PT Holcim Indonesia berdampak pada terjadinya perbaikan dalam hal pengurusan Posdaya serta kemandirian ekonomi masyarakat; Penelitian Hudaifah (2016) terkait program CSR yang dilakukan Forum CSR Jawa Timur dalam bentuk bantuan microfinance terhadap masyarakat dapat meningkatkan kompetensi 
masyarakat sebagai wirausahawan mikro sehingga terjadi peningkatan kesejahteraan Bantuan pinjaman modal yang diberikan oleh BUMN tentu saja sangat berperan membantu peningkatan laba usaha. Kenyataanya menunjukan terdapat kenaikan laba dari UMKM Mitra Binaan dari sebelum mendapat pinjaman dana dari Program Kemitraan BUMN. Perbandingan sesudah dapat pinjaman dana, merupakan bukti bahwa terjadi perkembangan usaha Mitra Binaan. Tetapi ada bebarapa UMKM yang tidak seberapa signifikan peningkatan labanya, karena modal yang diberikan terlalu sedikit. Pengaruh besarnya modal juga berpengaruh signifikan, karena dalam dunia bisnis yang kompleks, masih banyak faktor yang mempengaruhi perkembangan UMKM, mulai dari faktor eksternal dan faktor internal usaha, ditambah lagi dengan enterpreneur skill masing masing individu berbeda. Jika terjadi penurunan laba,itu disebabkan karena adanya kompetisi usaha yang begitu ketat sehingga mengharuskan Mitra Binaan melakukan peningkatan kualitas bahan baku,sehingga meningkatnya biaya produksi dan berakibat berkurangnya laba usaha.

Penelitian Ria dan Yusuf (2014) pada program CSR PT Pertamina EP menemukan bahwa program yang dilakukan telah mampu memberdayakan masyarakat membangun ekonomi mandiri yang berkesinambungan; Penelitian Natalia dan Andono (2014) dalam bentuk evaluasi CSR PT Charoen PhokPand Indonesia menunjukkan adanya peningkatan kesejahteraan masyarakat yang mengelola limbah tumpi. Penelitian Danhudi (2013) menemukan adanya peningkatan kesehatan Usaha Koperasi KPRI Dinas Perhubungan dan LLAJ Surabaya setelah mendapat bantuan CSR dari Bank Danamon;

Adapun langkah-langkah yang umumnya dilakukan perusahaan-perusahaan yang melakukan CSR dalam bentuk bantuan dana hibah maupun bantuan teknis serta pelatihan microfinance, antara lain adalah:

a) Perusahaan menugaskan karyawannya yang mempunyai kemampuan, komitmen, yang diserahi tanggung jawab (person in charge/PIC) terhadap CSR yang berkaitan dengan microfinance, atau dari bagian lingkungan.

b) Melakukan kegiatan monitoring pada pelaksanaan dan pada kemajuan kegiatan CSR microfinance sesuai dengan mekanisme monitoring yang sudah direncanakan.

c) Melakukan evaluasi kegiatan CSR microfinance, terutama pada programprogram yang telah berjalan, dan sekaligusmendokumentasian kemajuan dan keberhasilan yang telah dicapai.

d) Merumuskan kegiatan-kegiatan untuk menjamin agar kegiatan CSR microfinance yang sedang dan telah berjalan dapat dilanjutkan pada tahuntahun yang akan datang.

\section{SIMPULAN DAN SARAN}

Berdasarkan hasil penelitian-penelitian yang telah dilakukan dari sumber sampel yang didapatkan mengungkapkan bahwa sebagaian besar menemukan ada dampak yang signifikan dari CSR yang dilakukan perusahaan terhadap peningkatan kesejahteraan ekonomi masyarakat sebelum menerima program CSR yang artinya Program CSR yang telah dilakukan oleh perusahaan-perusahaan dapat menjadi motor penggerak peningkatan ekonomi masyarakat Indonesia pada umumnya dan masyarakat yang mendapat program CSR dari berbagai perusahaan di Indonesia pada khususnya. Penelitian juga menyimpulkan bahwa kegiatan CSR dalam bentuk pengembangan sumber daya manusia memiliki dampak yang lebih besar bagi peningkatan kesejahteraan ekonomi masyarakat terutama dalam bentuk bantuan dana usaha dan pelatihan kewirausahaan berhasil meningkatkan kesejahteraan masyarakat penerima CSR. Harapan kedepannya dengan dorongan Pemerintah, CSR yang dilakukan perusahaan dapat lebih berfokus mengutamakan pada kegiatankegiatan pengembangan kesejahteraan ekonomi masyarakat sehingga dapat menjadi motor penggerak perekonomian Indonesia dimasa yang akan datang. 
DAFTAR PUSTAKA

The European Commission. 2011, A renewed EU strategy 2011-2014 for corporate social responsibility. Brussels: European Commission, 2011b

Anonim. "Subsektor Layanan Komputer dan Piranti Lunak". Materi pada Focus Group Discusssion Pengembangan Ekonomi Kreatif Nasional. Jakarta, 1316 Desember 2011

Global Report Initiative (GRI). 2018. Sustainability Reporting Guidelines. www.globalreporting.org

Elkington, J. 2018, 25 Years Ago I Coined the Phrase "Triple Bottom Line." Here's Why it's Time to Rethink it. Harvard Business Review

Elkington, John. 2007. Cannibals with Forks: The Triple Bottom Line of $21^{\text {st }}$ Century Business. Oxford: Capstone Publishing

Hitt, M.A., Hoskisson, R.E., dan Ireland, R.D. (2007). Management of Strategy: Concepts and Cases. Mason: Thomson South Western.

Novita , Iriani. 2016, Dampak Pelaksanaan Program Corporate Social Responsibility (CSR) PT. Holcim Indonesia, Tbk Terhadap Masyarakat Lokal di Kabupaten Cilacap, Jurnal Kesejahteraan Sosial.

Republik Indonesia. 2007 Peraturan Menteri Badan Usaha Milik Negara No. PER05/MBU/2007 tentang Program Kemitraan Badan Usaha Milik Negara dengan Usaha Kecil dan Program Bina Lingkungan.

Pranoto, A., Yusuf, D. 2014, Program CSR Berbasis Pemberdayaan Masyarakat Menuju
Kemandirian Ekonomi Pasca Tambang di Desa Sarijaya, Jurnal IImu Sosial dan IImu Politik

Prajarto, Nunung. 2015, Corporate Social Responsibility and the Development of

Media, Design and Technology-Based Creative Economy,IPTEK-KOM, Vol. 17 No.2

Danhudi, D. 2013, Dampak Corporate Sosial Responsibility (CSR) Terhadap Tingkat Kesehatan Koperasi Pegawai Republik Indonesia Dinas Perhubungan dan LLAJ Provinsi Jawa Timur di Surabaya. STIE Perbanas Surabaya.

Komite Nasional Kebijakan Governance 2006. Pedoman Umum Good Corporate Governance Indonesia

Hudaifah, A. 2016, Pendekatan Terintegrasi Corporate Social Responsibility Perbankan Syariah dalam Pengentasan Kemiskinan di Jawa Timur, Al Tijarah Vol.2.

Natalia, D, F., Andono. 2014, Evaluasi Tahap Tahap Corporate Social Responsibility Pada PT Charoen PhokPand Indonesia di Surabaya. Economics And Business Research Festival

Maharani, Satia Nur. 2014, Sustainability Reporting sebagai Media Perusahaan dalam Mengembangkan dan Melaporkan Kebijakan Bisnis Berkelanjutan. Modernisasi, Vol10, Nomor 1, Februari 2014. Fakultas Ekonomi Universitas Negeri Malang.

Loh, I., Thao,N,T,P., Sim, I., Thomas, T.,Yu, W. 2016 Sustainability Reporting in Asean. National University of Singapore.

Kotler, P. (2011). Corporate Social Responsibility: Six Option for Doing Good. New York: Free Press 